\section{International Overdose Awareness Day - August 31, 2019}

August 31, 2019, is International Overdose Awareness Day, a global event that aims to raise awareness that overdose death is preventable and to reduce the stigma associated with drug-related death. Goals also include providing information about risk for overdose and community services and preventing drug-related harm through evidence-based policy and practice (https://www.overdoseday.com).

The opioid overdose epidemic, which killed 47,600 U.S. persons in 2017, ${ }^{*}$ substantially expanded in 2013 driven by rapid increases in overdose deaths involving synthetic opioids (excluding methadone), particularly illicitly manufactured fentanyl. ${ }^{\dagger}$ Cocaine and methamphetamine overdose deaths co-involving synthetic opioids also rapidly increased during this period (1).

A report in this issue of $M M W R$ documented decreases in opioid-involved overdose deaths in 25 states from JulyDecember 2017 to January-June 2018, especially those involving fentanyl analogs and prescription opioids. Overdose deaths involving illicitly manufactured fentanyl (including those co-occurring with illicit opioids and stimulants) increased (2). Improved identification of persons at high risk for overdoses involving illicitly manufactured fentanyl and linkage to risk-reduction services and evidence-based treatment are critical to reducing opioid deaths. Further information on CDC's state efforts and overdose data is available at https://www.cdc.gov/drugoverdose/index.html.

*https://www.cdc.gov/drugoverdose/data/statedeaths.html.

$\dagger^{\dagger}$ https://www.cdc.gov/drugoverdose/epidemic/index.html.

\section{References}

1. Kariisa M, Scholl L, Wilson N, Seth P, Hoots B. Drug overdose deaths involving cocaine and psychostimulants with abuse potential—United States, 2003-2017. MMWR Morb Mortal Wkly Rep 2019;68:388-95. https://doi.org/10.15585/mmwr.mm6817a3

2. Gladden RM, O'Donnell J, Mattson C, Seth P. Changes in opioidinvolved overdose deaths by opioid type and presence of benzodiazepines, cocaine, and methamphetamine-25 states, JulyDecember 2017 to January-June 2018. MMWR Morb Mortal Wkly Rep 2019;68:737-44.

\section{Changes in Opioid-Involved Overdose Deaths by Opioid Type and Presence of Benzodiazepines, Cocaine, and Methamphetamine - 25 States, July- December 2017 to January-June 2018}

\author{
R. Matt Gladden, $\mathrm{PhD}^{1}$; Julie O’Donnell, $\mathrm{PhD}^{1}$; \\ Christine L. Mattson, $\mathrm{PhD}^{1}$; Puja Seth, $\mathrm{PhD}^{1}$
}

From 2013 to 2017, the number of opioid-involved overdose deaths (opioid deaths) in the United States increased 90\%, from 25,052 to 47,600 * $^{*}$ This increase was primarily driven by substantial increases in deaths involving illicitly manufactured fentanyl (IMF) or fentanyl analogs ${ }^{\dagger}$ mixed with heroin, sold as heroin, or pressed into counterfeit prescription pills (1-3). Methamphetamine-involved and cocaine-involved deaths that

\footnotetext{
*https://www.cdc.gov/nchs/data/databriefs/db329_tables-508.pdf\#4.

$\dagger$ Fentanyl is a synthetic opioid 50-100 times more potent than morphine and is approved for treatment of severe (typically advanced cancer) pain. Illicitly manufactured fentanyl is manufactured illegally and sold through illegal drug markets for its heroin-like effect. Fentanyl analogs, also known as fentanylrelated substances, are synthetic opioids that are similar in chemical structure to fentanyl but modified to generate distinct substances. Fentanyl analogs vary in potency, with some more potent than fentanyl and others with potency similar to or less than fentanyl. https://www.cdc.gov/drugoverdose/opioids/ fentanyl.html; https://www.deadiversion.usdoj.gov/drug_chem_info/frs.pdf.
}

\section{INSIDE}

745 Racial Disparities in Breastfeeding Initiation and Duration Among U.S. Infants Born in 2015

749 Notes from the Field: Mumps in Detention Facilities that House Detained Migrants — United States, September 2018-August 2019

751 Notes from the Field: Multistate Outbreak of Salmonella Agbeni Associated with Consumption of Raw Cake Mix — Five States, 2018

753 QuickStats

Continuing Education examination available at https://www.cdc.gov/mmwr/cme/conted_info.html\#weekly.

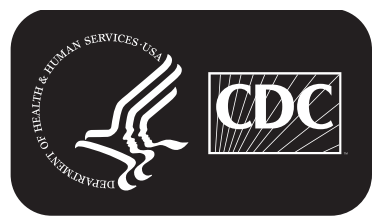

